\title{
ANTITUMOR ANTIBIOTICS PRODUCED BY PENICILLIUM STIPITATUM THOM
}

\author{
J. Fuska, I. Kuhr*, P. Nemec and A. Fuskoví \\ Department of Microbiology and Biochemistry, Faculty of Chemistry, \\ Slovak Polytechnical University, Bratislava, and \\ *Institute of Veterinary Medicine, Brno, \\ Czechoslovakia
}

(Received for publication August 25, 1973)

\begin{abstract}
A new crystalline antibiotic designated PSX-1 has been isolated from the fermentation broth of Penicillium stipitatum Thом. Antibiotic PSX-1 is a neutral reddish substance melting at $33 \sim 34^{\circ} \mathrm{C}$, containing only $\mathrm{C}, \mathrm{H}$ and $\mathrm{O}$. ( $\lambda_{\max } .207$ and $270 \mathrm{~nm}$ in methanol). The other crystalline antibiotic identified as duclauxin was isolated from the filtrate of the above-mentioned strain. Both antibiotics showed an inhibitory effect on EHRLICH ascites carcinoma (EAC), lymphadenoma L-5178 and sarcoma 37.
\end{abstract}

The production of potential cancerostatic substances in a larger group of Fungi imperfecti was studied, using a method based on inhibition of incorporation of ${ }^{14} \mathrm{C}$-labelled adenine and $l$-valine into EAC cells ${ }^{1}$. Penicillium stipitatum THом was one of the tested cultures whose filtrates showed an observable activity on EAC cells. The known metabolites of this mould-tropolonesstipitatic acid ${ }^{2)}$, stipitatonic acid ${ }^{32}$ and stipitalid ${ }^{4)}$ were isolated from the filtrates of given strain as well as the ethyl ester of stipitatic $\operatorname{acid}^{5,6)}$ showed no activity in the used screening test. The cancerostatic activity of filtrates detected, depended on the presence of some metabolites, yet unknown, of non-tropolone character.

\section{Production and Isolation}

A medium containing $9 \%$ sucrose, $1 \%$ corn-steep liquor ( $65 \%$ dry weight), $0.2 \% \mathrm{NaNO}_{3}$, $0.1 \% \mathrm{KH}_{2} \mathrm{PO}_{4}, 0.05 \% \mathrm{KCl}, 0.05 \% \mathrm{MgSO}_{4} \cdot 7 \mathrm{H}_{2} \mathrm{O}$ and $0.001 \% \mathrm{FeSO}_{4} \cdot 7 \mathrm{H}_{2} \mathrm{O}$ adjusted to $\mathrm{pH} 6.3$ was found to be suitable for the growth of inoculum. Strain CBS 375.48 was cultivated in $100 \mathrm{ml}$ of the medium, inoculated with $2.5 \mathrm{ml}$ spore suspension, and placed in $500 \mathrm{ml}$ shake flasks at $28^{\circ} \mathrm{C}$ for 42 hours. Four hundred $\mathrm{ml}$ of vegetative inoculum thus prepared was inoculated in 10 liters of the same medium in a small fermentor of 20 -liter volume and cultivated for 30 hours at $28^{\circ} \mathrm{C}$ with aeration of 7.5 liters $/ \mathrm{min}$. and stirring at $300 \mathrm{r}$.p.m. Sixteen liters of the culture thus obtained were inoculated into 300 liters of medium containing $5 \%$ glucose, $0.2 \% \mathrm{NaNO}_{3}, 0.1 \% \mathrm{KH}_{2} \mathrm{PO}_{4}$, $0.5 \% \mathrm{KCl}, 0.05 \% \mathrm{MgSO}_{4} \cdot 7 \mathrm{H}_{2} \mathrm{O}$ and $0.001 \% \mathrm{FeSO}_{4} \cdot 7 \mathrm{H}_{2} \mathrm{O}$ adjusted $\mathrm{pH}$ to 6.3 in a stainless steel fermentor of 500 -liter volume. The fermentation was continued for 120 hours at $28^{\circ} \mathrm{C}$ with aeration of 225 liters/min. and stirring at 220 r.p.m.

The mycelial cake was collected by filtration. The clear filtrate (190 liters, pH 4.0) was stirred for 30 minutes with 90 liters of tetrachloromethane at $22 \sim 24^{\circ} \mathrm{C}$. The tetrachloromethane layer was separated, clarified by centrifugation and dried by filtration through anhydrous $\mathrm{Na}_{2} \mathrm{SO}_{4}$. The obtained solution was concentrated under reduced pressure to $500 \mathrm{ml}$ and the concentrate was allowed to stand at $5^{\circ} \mathrm{C}$ overnight. From the concentrated extract the substance $\mathrm{X}-2$ with a strong 
cytotoxic activity crystallized as a pale yellow powder $(5.0 \mathrm{~g})$. The crude substance was purified on a column with silica gel and $1.8 \mathrm{~g}$ pure colorless crystalline antibiotic was obtained and identified as duclauxin ${ }^{7)}$.

The culture filtrate remaining after tetrachloromethane extraction was stirred three times with 80 liters of chloroform in the same procedure as given above. The extracts were combined and the solvent removed under reduced pressure. One hundred and twenty $\mathrm{ml}$ of red-brown syrup (33\% dry weight), was purified by column chromatography on silica gel: Forty $\mathrm{ml}$ residue were put on the top of the column $(\phi 35 \mathrm{~mm})$ with silica gel ( $300 \mathrm{~g}$ silica gel "L" Lachema), which was gradually eluted with a mixture of chloroform-methanol 100:5 (rate of elution $2 \mathrm{ml} / \mathrm{min}$.) and the fractions of $20 \mathrm{ml}$ were collected. The TLC on silica gel plates (Silufol ${ }^{\mathrm{R}}$ ) in the systems chloroform-methanol 100:5 and 10:1, with subsequent detection by $\mathrm{FeCl}_{3}$ and $\mathrm{KMnO}_{4}$ solution were used for estimating the presence of active substance. The biological activity of single fractions was simultaneously evaluated from the point of view of inhibition of incorporation of the ${ }^{14} \mathrm{C}$-labelled adenine and $l$-valine into EAC cells ${ }^{1)}$. The fractions Nos. 35 40 effective only on EAC cells containing mainly a spot with $\mathrm{R}_{\mathrm{f}} 0.5$ in chloroform-methanol $10: 1$ system were combined and evaporated in vecuo. In this procedure $8.3 \mathrm{~g}$ of active fraction was obtained in the form of reddish oil, which did not crystallize standing some days at $0^{\circ} \mathrm{C}$. The viscous residue (oil) was again purified by the same procedure. The collected fractions containing only the spot $R_{f} 0.5$ were combined evaporated under reduced pressure as described above. A final yield of $2.8 \mathrm{~g}$ substance in the form of reddish syrup was obtained from which the active antibiotic in the form of faintly reddish plates was crystallized.

\section{Physical and Chemical Properties}

Antibiotic PSX-1 was obtained as faintly reddish crystals, melting at $33 \sim 34^{\circ} \mathrm{C}$. The optical rotation is $[\alpha]_{\mathrm{D}}^{22}+182^{\circ}$ (c 1.0, chloroform). The molecule contains carbon, hydrogen and oxygen. The ultraviolet absorption spectrum of PSX-1 substance is shown in Fig. 1, indicating two maxima of 207 and $270 \mathrm{~nm}$ (with $\mathrm{E}_{1 \mathrm{~cm}}^{1 \%} 88$ and 45 in methanol). The infrared absorption spectrum in a potassium bromide pellet is given in Fig. 2. The antibiotic is readily soluble in chloroform, moderately in acetone, methanol and ethanol, slightly in benzene. It is insoluble in water and petroleum ether. When the antibiotic was examined by thin-layer chromatography using silica gel plates $\left(\right.$ Silufol $\left.^{R}\right)$ in the solvent system chloroform-methanol $10: 1$ a single spot detected with $2.4 \mathrm{DNPH}$ and $\mathrm{KMnO}_{4}$ was observed. When the TLC are allowed to stand for 30 60 minutes in the open air the antibiotic can be detected as a deep red spot. The substance gives no clolor reaction with $\mathrm{FeCl}_{3}$ and diazoted benzidine. Substance PSX-1 is moderately stable, it decomposes partially in the open air (red spot). In the solution methanol, ethanol and acetone after standing or after

Fig. 1. Ultraviolet absorption spectrum of PSX-1 (in methanol)

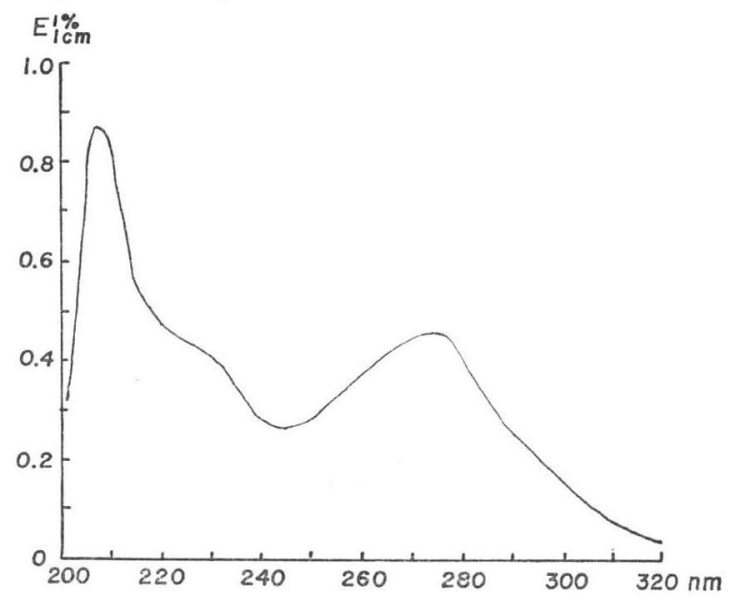


heating some reddish spots $R_{\mathrm{f}} 0.61$ and 0.74 occur TLC in silica gel in system chlorofom-methanol $10: 1$.

\section{Biological Properties of PSX-1 and Duclauxin}

The potential antitumor effect of PSX-1 and duclauxin was evaluated in vitro using EHRLich ascites carcinoma, lymphadenoma L-5178 and sarcoma 37. The effect was evaluated according to the decrease of the amount of nucleic acids in the tumor cells $^{8)}$ (Table 1). Both antibiotics suppressed the growth of HeLa cells and the cytotoxic effect was estimated by a modified Oyama and Eagle

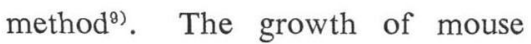
embryonic fibroblasts (LWF) as well as growth of malignant transformed cells by Rous sarcoma virus were inhibited, when the substance PSX-1 was added to the growth medium.

Both substances caused the inhibi-
Fig. 2. Infrared absorption spectrum of PSX-1 (in KBr tablet)

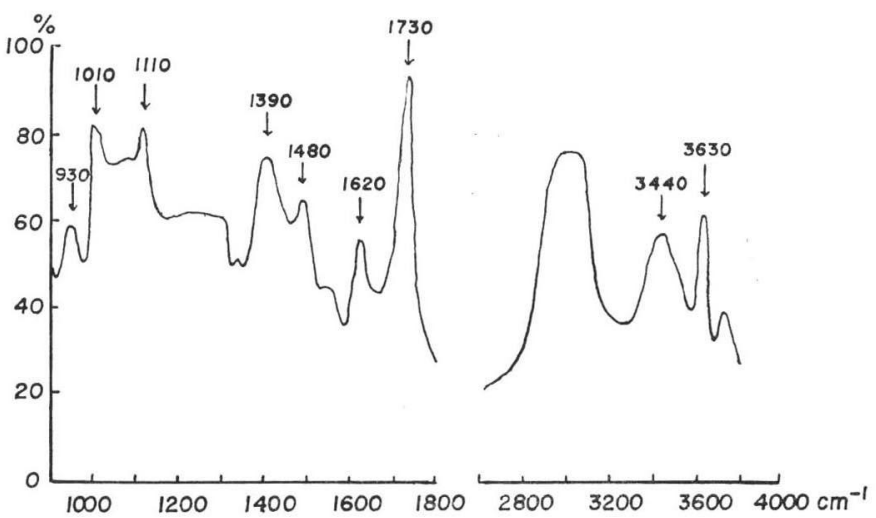

Table 1. Antitumor activity of antibiotic PSX-1 and duclauxin in vitro

\begin{tabular}{l|c|c}
\hline \multirow{2}{*}{ Type of tumor } & \multicolumn{2}{|c}{$\mathrm{ED}_{50}(\mu \mathrm{g} / \mathrm{ml})$} \\
\cline { 2 - 3 } & $\mathrm{PSX}-1$ & duclauxin \\
\hline EHRLICH ascites carcinoma* & 0.58 & 20.0 \\
Lymphadenoma L-5178* & 0.78 & 20.0 \\
Sarcoma 37* & 1.50 & $=$ \\
Rous sarcoma & 50.00 & $=$ \\
HeLa & 2.0 & 50.0 \\
\hline
\end{tabular}

* The results were obtained by Dr. L. P. IvanitskAYA, Institute of New Antibiotics, Academy of Medical Sciences, Moscow, USSR. tion of incorporation of ${ }^{14} \mathrm{C}$-labelled precursors of proteins and nucleic acids into EAC cells ${ }^{1)}$ (Fig. 3). The RNA synthesis in EAC cells was more inhibited than DNA synthesis when the substance PSX-1 was present in suspension cells (Fig. 4).

Antibiotic PSX-1 and duclauxin were slightly active against Bacillus subtilis (in concentration $250 \mu \mathrm{g} / \mathrm{ml}$ ) and inactive against Escherichia coli, Euglena gracilis and Astasia longa. PSX-1

Fig. 3. Inhibition of incorporation of ${ }^{14} \mathrm{C}$-labelled precursors into EAC cells by PSX-1

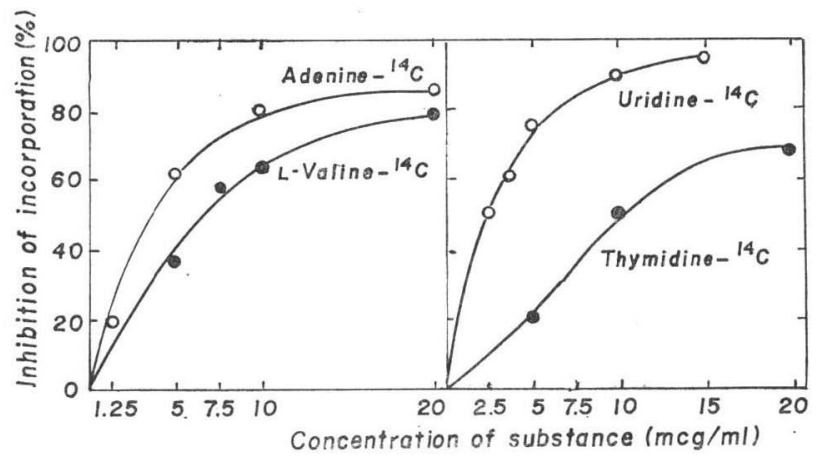

Fig. 4. Inhibition of incorporation of ${ }^{14} \mathrm{C}$-labelled precursors into EAC cells by duclauxin $(\mathrm{X}-2)$

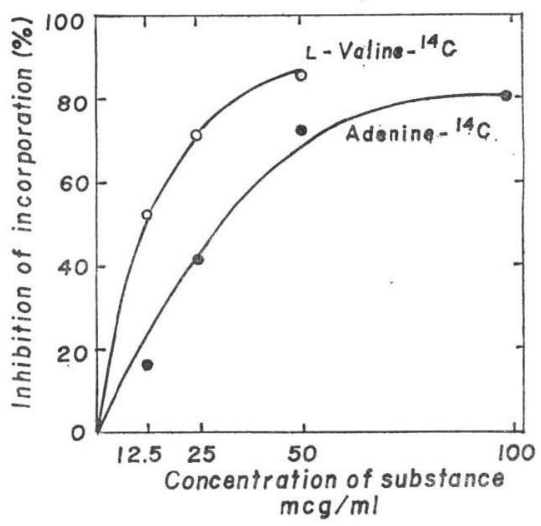


inhibited the growth of Candida pseudotropicalis in concentration $50 \mu \mathrm{g} / \mathrm{ml}$ and the growth of Trypanosoma cruzi in concentration $100 \mu \mathrm{g} / \mathrm{ml}$.

\section{Discussion}

Strain Penicillium stipitatum CBS 375.48 produced about 15 metabolites into the filtrate. More than ten substances with non-tropolone character can be found in the chloroform extracts, using TLC chromatography. These substances differ from the metabolites which have the structure of tropolones and which in the solvent systems used, remain at the beginning of the chromatogram, and most of them can be detected with $\mathrm{FeCl}_{3}$ and diazoted benzidine. The isolated antibiotics PSX-1 and duclauxin are the main components with antitumor activity, though antitumor effect was shown also by some other fractions. The metabolites found in these fractions are present in the medium in small concentrations and their isolation is rather difficult and they have not yet been isolated.

Duclauxin and PSX-1 were found in the filtrates of the culture growing in various media. CZAPEK-Dox medium with glucose proved, to be the most suitable medium for their preparation. However, in this medium the strain produces only as mall amount of stipitatonic acid and stipitalid, which are extracted together with active substances into chloroform.

The physico-chemical properties of PSX-1 showed that the substance cannot be identical with the known tropolone metabolites ${ }^{15)}$ or with duclauxin, a modified phenalenone ${ }^{10,11)}$ produced by Penicillium stipitatum. The antibiotic differs from all non-tropolone metabolites produced by Penicillium stipitatum ${ }^{12,13,14,15,16)}$. According to the physico-chemical properties the substance is probably not identical with any of the known and described fungel metabolites ${ }^{17,18)}$.

The authors are grateful to Mrs. M. Adamkova and J. Strossova for technical assistance through this work.

\section{References}

1) Fuska, J.; M. Miko, P. Nemec \& L. Drobnica: Screening of the cytotoxic action of fungus filtrates on EHrLICH's ascites carcinoma, utilizing ${ }^{14} \mathrm{C}$-labelled precursors. Neoplasma $18: 631 \sim 636,1971$

2) Birkinshaw, J. H.; A. R. Chambers \& H. Raistrick: Studies in the biochemistry of microorganisms. 70. Stipitatic acid, $\mathrm{C}_{8} \mathrm{H}_{8} \mathrm{O}_{5}$, a metabolic product of Penicillium stipitatum Thom. Biochem. J. 36 : 242 251, 1942

3) Segal, W.: Stipitatonic acid. A new mould tropolone from Penicillium stipitatum Thом. J. Chem. Soc. $1959: 2847 \sim 2851,1959$

4) HoLik, M. \& I. KuHr: Determination of the structure of stipitalide, a new tropolone of Penicillium stipitatum Тном. Chem. Commun. 1973: 65 66, 1973.

5) Divekar, P. V.; P. E. Brenneisen \& S. W. Tanenbaum: Stipitatic acid ethyl ester: a naturally occurring tropolone derivative. Biochem. Biophys. Acta $50: 588 \sim 589,1961$

6) Bentley, R. \& J. G. Keil: Biosynthesis of tropolones in Penicillium stipitatum. IV. The reactions of tropolone dicarboxylic acid anhydrides with alcohols. J. Biol. Chem. $238: 3806 \sim 3810,1963$

7) Kuhr, I.; J. Fuska, P. Sedmera, M. Podojil, J. Vokoun, Z. Vaněk: An antitumor antibiotic produced by Penicillium stipitatum Tном: Its identity with duclauxin. J. Antibiotics 26: 535 536, 1973

8) Ivanitakaya, L. P.; L. V. Makukho, N. V. Klitsunova \& O. K. Rossolimo: The problem of screening antibiotics inhibiting synthesis of nucleic acids. Antibiotics (Russian) $16: 115 \sim 119,1971$

9) Oyama, V.I. \& H. Eagle: Measurement of cell growth in tissue culture with phenol reagent (FolinCiocalteau). Soc. Exp. Biol. Med. Proc. $91:$ 305 307, 1956

10) Shibata, S.; Y. Ogihara, N. Tokutake \& O. Tanaka: Duclauxin, a new metabolite of Penicillium duclauxi (Delacroix). Tetrahedron Letters $1965: 1287 \sim 1288,1965$

11) Ogihara, Y.; O. Tanaka \& S. Shibata: On the metabolites of Penicillium duclauxi (Delacroix). III. The reaction of duclauxin with ammonia and primary amines. The structure of desacetyl-duclauxin, neoduclauxin, xenoclauxin and cryptoclauxin. Tetrahedron Letters $1966: 2867 \sim 2873,1966$

12) Brenneisen, P. E.; T. E. Acker \& S. W. TANenbaum: Isolation and structure of a methyltriacetic acid lactone from Penicillium stipitatum. J. Chem. Soc. $86: 1264 \sim 1265,1964$ 
13) Bentley, R. \& P. M. Zwitkowits: Biosynthesis of tropolones in Penicillium stipitatum. VII. The formation of polyketide lactones and other nontropolone compounds as a result of ethionine inhibition. J. Am. Chem. Soc. $89: 676 \sim 680,1967$

14) TAnenbaum, S. W.: Reflection on the fungal formation of acetate-derived metabolites. In Z. VANĚK and Z. HošTǎLeK (eds) Biogenesis of antibiotic substances, Prague 1965, pp. 143 153

15) Scott, A. I.H.; H. Guilford \& E. LeE: Biosynthesis of the fungal tropolones. Stipitatic acid and stipitatonic acids. J. Am. Chem. Soc. 93 : 3535 3536, 1971 (and references cited)

16) Lavate, W. V.; J.R. Dyer, C. M. Springer \& R. Bentley: Studies on coenzyme Q. The isolation, characterization, and general properties of a partly reduced coenzyme $\mathrm{Q}_{10}$ from Penicillium stipitatum. J. Biol. Chem. $240: 524 \sim 531,1965$

17) Shibata, S.; S. Natori \& S. Udagawa: List of fungal products. Charles C. Thomas Publisher, Springfield, Illinois, 1964

18) Turner, W. B.: Fungal metabolites. Academic Press. New York and London, 1971 